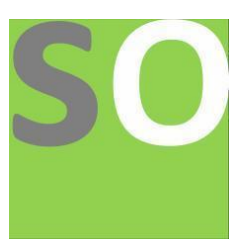

Article title: Determining the Magnitude of Wind Loads on Structures in Kenya according to the Eurocodes Authors: Muthomi Munyua[1]

Affiliations: University of Nairobi[1]

Orcid ids: 0000-0002-5786-4032[1]

Contact e-mail: muthomimunyua@gmail.com

License information: This work has been published open access under Creative Commons Attribution License http://creativecommons.org/licenses/by/4.0/, which permits unrestricted use, distribution, and reproduction in any medium, provided the original work is properly cited. Conditions, terms of use and publishing policy can be found at https://www.scienceopen.com/.

Preprint statement: This article is a preprint and has not been peer-reviewed, under consideration and submitted to ScienceOpen Preprints for open peer review.

Funder: Self

DOI: 10.14293/S2199-1006.1.SOR-.PPBRJ1U.v2

Preprint first posted online: 12 January 2021

Keywords: Eurocodes, Wind, Kenya, Economic, Design, Gusts, CP3 


\title{
Determining the Magnitude of Wind Loads on Structures in Kenya according to the Eurocodes
}

\author{
Muthomi Munyua \\ School of Engineering, University of Nairobi \\ P.O. Box 30197 - 00100, Nairobi, Kenya \\ Email: muthomi@uonbi.ac.ke
}

\begin{abstract}
This study provided guidance on the use of existing wind data in Kenya with the Eurocodes despite the absence of the local national annexes. The determination of wind loads in the structural design of buildings according to the Eurocode Standard KS EN 1991-1-4:2005 had several challenges. The code of practice commonly used in Kenya was CP3-Chapter V-2:1972 that used the three-second gust duration. This gust duration resulted in higher magnitudes of wind loads that ended up making the structures unnecessarily robust and uneconomical. Using the Eurocodes had the promise of achieving more economical designs because it used the 10-minute gust duration. The 10-minute gust duration resulted in typically lower magnitudes of wind loads than the three-second gust duration for the same wind speed. Kenya adopted the Eurocodes in September 2012 but had not yet developed its national annexes opting instead to use the UK National Annexes. The UK National Annexes were applicable to Kenya in some scenarios but not in others such as wind loading. The lack of the Kenya National Annexes led to difficulties in the adoption of the Eurocodes. This paper outlined a procedure in which the existing wind data given in three-second gusts could be converted to 10-minute wind speeds. Once converted, the method described in the UK National Annex could then be followed selectively to determine the wind load on a structure. Lastly, the paper recommended that wind data collected from 1977 to 2021 by the Kenya Meteorological Department be incorporated to the development of the wind map for the Kenya National Annex to KS EN 1991-1-4:2005.
\end{abstract}

Keywords: Eurocodes, Wind, Kenya, Gusts, CP3

\section{Introduction}

\subsection{Background}

Wind actions are one of the loads that are of great significance in determining the stability of structures. There are two main methods of quantifying wind speeds: sustained wind speeds and wind gusts. Sustained winds speeds are the steady or average wind speeds over a duration of time usually over a 10-minute duration. The United States of America (USA) preferred a one-minute duration for sustained wind speeds. Wind gusts are sudden increases in wind speeds that are transient and last for less than 20 seconds [1]. Wind gusts are usually about $30 \%$ stronger than sustained wind speeds [2]. Wind gusts are quite variable and depend on different dynamics such as location and terrain. Sustained wind speeds give a more accurate idea of how steady the wind speed is as opposed to wind gusts.

\subsection{Problem Statement}

Developers in Kenya avoided the services of professional engineers mainly because of the following reasons related to cost: engineering services were perceived to be expensive in comparison to services offered by experienced technicians; and engineering specifications were deemed to be unnecessarily conservative, resulting in additional expenses.

This paper focused on the magnitude of wind actions/loads applied to structures in Kenya in line with the local regulations. The magnitude of the loads at the design stage contribute significantly to the cost of the construction project. The practice in Kenya was to use the three-second wind gusts which are higher in magnitude than the sustained wind speeds.

Kenya adopted the Eurocodes on $14^{\text {th }}$ September 2012 via Gazette Notice No. 13048 [3]. The Eurocodes were a set of harmonised European standards for the design of buildings and civil engineering structures. The specific Eurocode standard for wind loading was KS EN 1991-1-4:2005 - Eurocode 1: Actions of Structures Part 1-4: General actions - Wind actions. KS EN 19911-4:2005 specified that the10-minute wind speed was to be used [4]. Wind data available locally was provided by the standardisation body, Kenya Bureau of Standards (KEBS), and the weather monitoring service, Kenya Meteorological Department (KMD) and were in threesecond gusts. To a structural engineer, the main problem was inadequate guidance on how to convert threesecond gusts to 10-minute wind speeds. The objective of this paper was to provide a procedure on how to determine the magnitude of wind loads on structures in Kenya when designing to the Eurocodes.

\subsection{Justification of the Study}

The main justification of this study was that the Eurocodes were adopted in Kenya without the relevant corresponding National Annexes. The study demonstrated how to modify existing wind speeds provided in three-second gusts by both KEBS and KMD, to 10-minute wind speeds. 


\subsection{Scope}

The study was limited to using existing data published by KEBS in 1977 [5]. However, due to the effects of climate change and other human activities such as deforestation, there was a high likelihood that this wind data was outdated by 2021. Unfortunately, the wind data published in 1977 was still in use in Kenya by January 2021.

\section{Methodology}

This paper was formulated through a desk study that looked into the process of determining the magnitude of wind loads on structures in Kenya and compared it with the process used in the United Kingdom of Great Britain and Northern Ireland (UK). The comparison with the UK was made because Kenya's engineering practice was heavily influenced by the UK's practice. The study relied on data from KEBS and the author's experience as a practising structural engineer in Kenya. Emphasis was put on areas where the UK practice did not apply to Kenya.

\subsection{The Practice in Kenya}

The practice in Kenya was based on a previous design code of the UK. That design code was CP3-Chapter V2:1972 - Code of Basic Data for the Design of Buildings [6]. Ideally, CP3-Chapter V-2:1972 should only have been used in the UK but its application found its way to Kenya. Kenya's engineers ignored the UK wind map in CP3-Chapter V-2:1972 and instead used Table 1 of the Kenya Standard KS 02-26:1977 [5] reproduced here as Table 1.

\begin{tabular}{|l|c|}
\hline Location & $\begin{array}{l}\text { Basic Wind } \\
\text { Speed (m/s) }\end{array}$ \\
\hline Coast province, Voi, Garissa & 31 \\
\hline Nairobi, Machakos, Kitui, Isiolo & 27 \\
\hline $\begin{array}{l}\text { Nakuru, Naivasha, Magadi, } \\
\text { Nanyuki, Rumuruti }\end{array}$ & 36 \\
\hline $\begin{array}{l}\text { Eldoret, Kitale, Narok, Magadi, Rift } \\
\text { Valley Province, Kisumu, Nyanza } \\
\text { Province, Western Province }\end{array}$ & 45 \\
\hline Table 1: Horizontal wind speeds at 10m above the surface [5].
\end{tabular}

Table 1 shows horizontal basic wind speeds of various locations and was used when determining wind speed at a site in Kenya. Table 1 had the following errors:

1. Magadi town was presented on two rows with a corresponding wind speed of $36 \mathrm{~m} / \mathrm{s}$ on the third row and $45 \mathrm{~m} / \mathrm{s}$ on the fourth row.

2. Data from Central Kenya was not presented.

3. All the towns in the third row (Nakuru, Naivasha, Magadi, Nanyuki and Rumuruti) were located in Rift Valley province with a corresponding wind speed of $36 \mathrm{~m} / \mathrm{s}$ while the fourth row showed data for Rift Valley province with a corresponding wind speed of $45 \mathrm{~m} / \mathrm{s}$.
Because of these discrepancies, there was a table used by some consulting engineers that aimed to address these errors.

\begin{tabular}{|l|c|}
\hline Region & $\begin{array}{l}\text { Basic Wind } \\
\text { Speed (m/s) }\end{array}$ \\
\hline $\begin{array}{l}\text { Nairobi, Central and Southern Half } \\
\text { of Eastern Province }\end{array}$ & 28 \\
\hline $\begin{array}{l}\text { Northern Half of Eastern and North } \\
\text { Eastern Province }\end{array}$ & 40 \\
\hline Coast Province & 31 \\
\hline Southern Part of Rift Valley & 36 \\
\hline Nyanza and Western Province & 46 \\
\hline \multicolumn{2}{|l|}{ Table 2: The corrected version of KS 02-26:1977 Table 1. } \\
\hline
\end{tabular}

Table 2 shows the basic wind speeds of five regions in Kenya. Despite the attempt to correct the errors present in Table 1, Table 2 omitted data for the Northern part of Rift Valley Province. The values in Table 2 had not been published officially by any authority [7], nonetheless, the table found widespread use among engineers in Kenya. The wind speeds in Table 2 were also based on a three-second gust duration.

Once the designer made the decision on the wind speed to use at a site using either Table 1 or Table 2, the procedure in the CP3-Chapter V-2:1972 was then followed to determine the magnitude of the wind load on the structure.

Information also worth noting was that KMD released wind speeds that slightly differed from the data published by KEBS [5]. These wind speeds were also given in three-second gusts and were presented in Table 3. Table 3 shows six towns in Kenya with their corresponding wind speeds over 25-year, 50-year and 100-year return periods.

\begin{tabular}{|l|c|c|c|}
\hline \multirow{2}{*}{$\begin{array}{l}\text { Town/Return } \\
\text { period in years }\end{array}$} & \multicolumn{3}{|c|}{ Wind speed (m/s) } \\
\cline { 2 - 4 } & $\mathbf{2 5}$ & $\mathbf{5 0}$ & $\mathbf{1 0 0}$ \\
\hline Mombasa & 25.9 & 28.1 & 30.3 \\
\hline Kisumu & 41.2 & 44.6 & 48.1 \\
\hline Nakuru & 29.0 & 31.3 & 33.9 \\
\hline Nanyuki & 33.1 & 35.9 & 38.7 \\
\hline Nairobi & 24.8 & 26.9 & 29.0 \\
\hline Kericho & 28.6 & 30.9 & 33.4 \\
\hline \multicolumn{4}{|c|}{ Table 3: Wind speeds for some towns in Kenya [8]. }
\end{tabular}

Table 1 and Table 2 did not indicate the probability of exceedance even though the 50-year return period was assumed. The 50-year return period was typically used for designing buildings [7]. A 50-year return period means that there was a 0.02 probability of exceedance, equivalent to a 50 year mean recurrence interval [9]. The wind speed in Table 1 was comparable to the wind speed on the highlighted column of Table 3 showing wind speeds for the 50 -year return period. 


\section{Decision after CP3 was declared obsolete by BSI} The British Standards Institute (BSI) declared CP3Chapter V-2:1972 obsolete in 1998 after it adopted BS 6399-2:1997 - Code of Practice for Wind Loads [10]. BSI was the UK's standardisation body and was the institution responsible for maintaining CP3-Chapter V2:1972. A significant change between CP3-Chapter V2:1972 and BS6399-2:2007 was the gust duration of three seconds and one hour respectively. Despite BSI's declaration, KEBS neither updated the wind speeds of Table 1 nor the design process of CP3-Chapter V2:1972. Over time, since CP3-Chapter V-2:1972 was declared outdated by BSI; some engineers in Kenya opted to use BS 6399-2:1997 with the same gust duration of three seconds. Whereas the use of the threesecond gust was indeed safer, it resulted in conservative designs that increased project costs. Engineers in Kenya continued to use data which was only fit for the obsolete standard CP3-Chapter V-2:1972 [10]. In March 2010, BSI withdrew BS 6399-2:1997, creating an avenue for the full adoption of the Eurocodes in the UK. Following the UK's withdrawal of BS 6399-2:1997, it was deemed important for Kenya to fully adopt the Eurocodes as well.

\section{The Design Codes used in Kenya}

As of January 2021, there were three design codes used in Kenya for the determination of wind loads. These design codes were CP3-Chapter V-2:1972, BS 63992:1997 and KS EN 1991-1-4:2005.

CP3-Chapter V-2:1972 [10] used a three-second gust duration, $V_{3}$, while the BS 6399-2:1997 [11] utilised a mean hourly gust duration, $V_{3600}$. KS EN 1991-14:2005 used a 10-minute gust duration, $V_{600}$ [4]. The nomenclature for the various wind speed durations was as proposed by the World Meteorological Organisation (WMO). The nomenclature followed that an estimate of the true mean wind $V$ should be explicitly identified by its averaging period $T_{0}$ in seconds, described as $V_{T_{0}}[12]$.

\begin{tabular}{|l|l|c|}
\hline Wind Code & Gust Period & Abbreviation \\
\hline CP3-Chapter V-2 & 3 seconds & $V_{3}$ \\
\hline BS 6399-2 & 1 hour & $V_{3600}$ \\
\hline EN 1991-1-4 & 10 minutes & $V_{600}$ \\
\hline
\end{tabular}

Table 4: Wind Design codes and the respective gust periods.

Table 4 illustrated the differences. It showed the wind code, the gust period and the WMO abbreviation. The use of the different gust periods posed a challenge to engineers when using any of the three design codes for structural design. CP3-Chapter V-2:1977 was obsolete and the wind data available for use was in different gust durations from the gust durations to be used with BS 6399-2:1977 and KS EN 1991-1-4:2005.

\subsection{Eurocode Adoption in Kenya}

The Eurocodes had Nationally Determined Parameters (NDPs) that every country had to provide for the effective use of the codes. These NDPs were typically published in separate documents from the actual Eurocode standards. Those separate documents were referred to as National Annexes. Unfortunately, Kenya had not yet developed such annexes. Engineers continued to use Table 1 when determining the wind speeds at a site.

Table 1 had wind speeds in three-second wind gusts. This gust period was used because of the response time of mechanical anemometers. The response time for anemometers was usually one to three seconds and was a function of the inertia of the system [12]. This response time was the main reason that several other countries, such as the UK, US and Australia, previously used the three-second gust duration when recording wind speeds [12].

The Eurocodes utilised 10-minute wind speeds [4]. A 10-minute gust duration is likely to be of lower speed than a three-second gust duration. This lower speed is due to the fact that over a longer period, mean velocities are lower since there is a high chance that a peak is cancelled out in the duration of the recording. Since the 10-minute gust is lower than the three-second gust, using the Eurocodes rather than using CP3-Chapter V$2: 1972$, could lead to the justification of more economical designs. The issue of conservativeness versus design efficiency and rationalising the use of resources was still a core question in the construction industry. Most building codes and standards, including the Eurocodes, have sided with safety and opted for more conservative designs. The gain in economy achieved by KS EN 1991-1-4:2005 did not compromise the safety of buildings. The decision that guided the reduction in the magnitude of the wind loads was based on science and research [13].

\subsection{UK National Annexes}

The Government of Kenya declared the Eurocodes as its national standards although Kenya's standardisation body, KEBS, had not yet developed the relevant annexes [3]. An article in The Kenya Engineer, the journal of the Institution of Engineers of Kenya (IEK), stated that the UK National Annexes (UK NA) were to be used with the adopted Eurocodes [14]. That article implicitly described the UK National Annexes as one single document. That implicit description was not accurate. There were several annexes to be used with the Eurocodes. Each specific part of the Eurocode was accompanied by its corresponding relevant annex. Statements made by Jane Maina, the manager of the Engineering Division (Civil and Mechanical engineering standards) of KEBS and Professor Stanley Shitote, the Chairman of the National Implementation 
Committee on the Eurocodes (NICE) in Kenya, confirmed that the Eurocodes were to be used in conjunction with the UK NA for the structural design of buildings civil engineering structures in Kenya [15]. The use of the UK NA, rather than the development of the Kenya NA, might have been advantageous to Kenya as it avoided duplication of efforts. Also, the resources that would have been used in repeat studies were diverted to the training of Kenya's engineers on the adoption and use of the Eurocodes.

The UK NA were applicable in Kenya in some situations but were not applicable in other scenarios such as that of temperature, wind or snow. Kenya and the UK had different climates. The local conditions of the two countries were quite different. The wind speed in the UK was usually read directly from a wind map in the UK NA [16]. The value of the wind speed read off from the wind map was then modified based on the season, wind direction and site altitude. The basic velocity pressure $q_{\mathrm{b}}$, was then calculated using Eqn (4.10) in KS EN 1991-1-4:2005. Eqn (4.10) was reproduced below as Expression (1):

$$
\text { basic velocity pressure, } q_{\mathrm{b}}=\frac{\rho v_{\mathrm{b}}^{2}}{2}
$$

where:

$$
\begin{array}{ll}
\rho- & \text { Density of air. } \\
v_{\mathrm{b}} & -\quad \text { Modified wind speed based on the season, } \\
& \text { wind direction and site altitude. }
\end{array}
$$

After that, the basic velocity pressure $q_{\mathrm{b}}$, was multiplied by the exposure factor $c_{\mathrm{e}}(z)$, as prescribed by Eqn (NA.3a) of the UK NA. Eqn (NA.3a), reproduced here as Expression (2), overrode Eqn (4.8) of KS EN 1991-1-4:2005. Eqn (4.8) was reproduced later in this paper as Expression (4). The product of the exposure factor $c_{e}(z)$ and the basic velocity pressure $q_{\mathrm{b}}$ resulted in the peak velocity pressure $q_{\mathrm{p}}$. This peak velocity pressure was the magnitude of the wind load that engineers used to design the structure.

$$
\text { peak velocity pressure, } q_{\mathrm{p}}=c_{\mathrm{e}}(z) \times q_{\mathrm{b}}
$$

where:

$$
\begin{array}{cl}
c_{\mathrm{e}}(z) & - \text { Exposure factor. } \\
q_{\mathrm{b}} & - \text { Basic velocity pressure }
\end{array}
$$

The exposure factor $c_{\mathrm{e}}(z)$ was specific to the UK and was a function of the distance to sea. The use of the exposure factor $c_{\mathrm{e}}(z)$ in Kenya would not be correct.

\section{Arguments against the use of the exposure factor $c_{\mathrm{e}}(z)$ of the UK NA in Kenya}

1. The UK NA was based on the fact that the UK was generally at a low-lying level with an average altitude of approximately $162 \mathrm{~m}$ above sea level. On the other hand, Kenya had an average altitude of $762 \mathrm{~m}$ above sea level [17]; significantly higher than the average altitude of the UK. In addition to that, several areas in Kenya were highlands with a mean sea level of $1500 \mathrm{~m}$ above sea level.

2. The UK wind map was based on a reference datum, the sea, hence the need for an altitude correction factor $c_{\text {alt }}$ proposed in the UK NA whereas the KS 02-26:1977 Table 1 gave speed at $10 \mathrm{~m}$ above the ground at a particular location [5]. The data in Table 1 was not based on a reference datum and there was therefore no need to apply the altitude correction factor $c_{\text {alt }}$ in Kenya.

3. The UK was an island and experienced marine climate throughout the entire country. The distance to the sea was therefore essential when determining the wind speed at a site. In contrast, Kenya was continental with significant geographical formations that influenced the wind pattern of that locality; consequently, the distance to sea was not the main factor affecting the wind speed.

4. The UK NA, as stated in Clause NA 2.18, used an air density value of $1.226 \mathrm{~kg} / \mathrm{m}^{3}$ [16] whereas this study found no predetermined value for the density of air in Kenya. KS EN 1991-1-4:2005 recommended a value of $1.25 \mathrm{~kg} / \mathrm{m}^{3}$ [4].

\section{Other Eurocode Challenges}

Kenya adopted all the Eurocodes, including the Snow Eurocode [3]. Kenya was at the equator and experienced tropical climate. The country hardly experienced any snowfall except around the peaks of Mt. Kenya that had an altitude of approximately 5,200 metres above sea level. These facts did not mean that KEBS erred in its adoption of the Snow Eurocode KS EN 1991-1-3:2004 [18]. Some parts of Kenya received hail which took several days to thaw [19]. Kericho, Laikipia, Nakuru, and Nyandarua counties had records of experiencing significant hail. Hail was covered in the Snow Eurocode KS EN 1991-1-3:2004.

A different Eurocode, KS EN 1991-1-5:2010, was the standard used for the determination of thermal actions on structures [20]. The temperature map for Kenya was also not yet been developed. The absence of this temperature map hampered Eurocode adoption in Kenya and made the determination of thermal loads, which was essential in the design of bridges, a challenging task.

\subsection{Kenya Wind Map}

There was no wind map used in the design of structures in Kenya, instead, the values from Table 1 were used to come with a wind map. The data given in KS 0226:1977 showed points and areas with the same wind speed. A map of these wind speeds was modelled and isotachs were drawn as shown in Figure 1. Isotachs are 
lines on a map with equal wind speeds [21]. The jurisdiction of the map was as per the Constitution of Kenya, 2010 [22]. Figure 1 showed a proposed wind map for Kenya. This map used the data published in 1977.

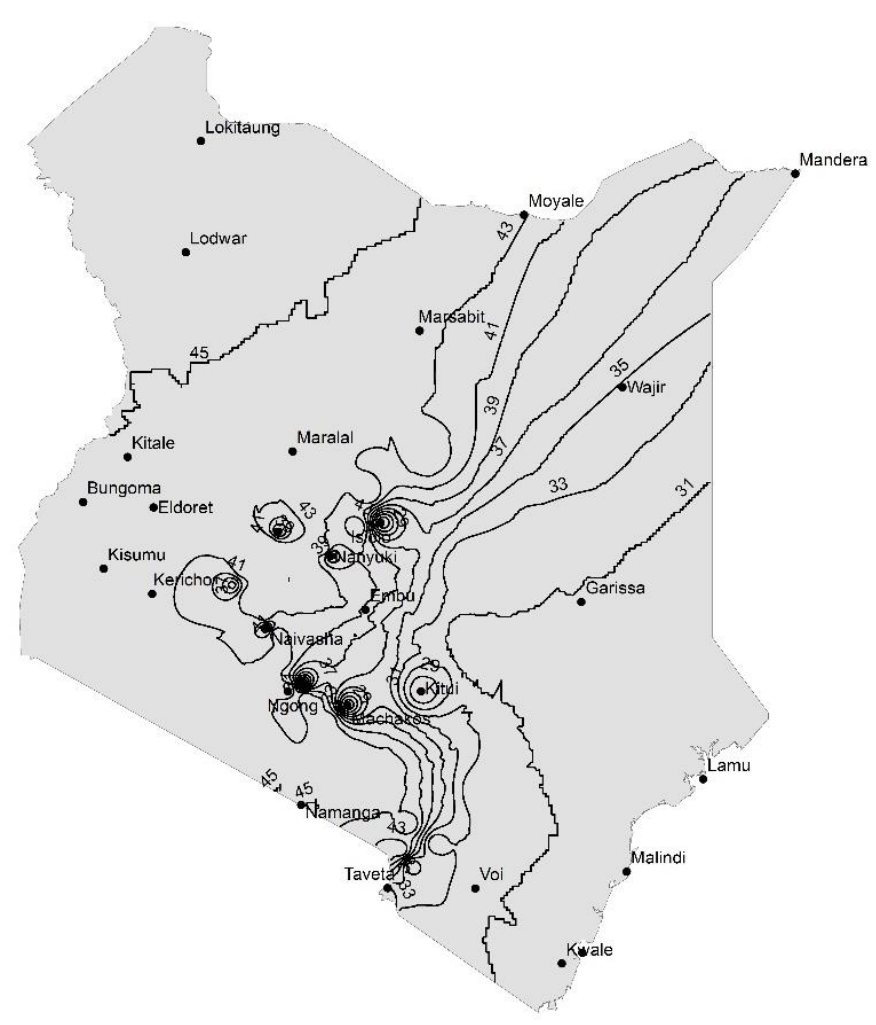

Figure 1: Isotachs generated from Table 1 of KS 02-26:1977.

It was essential to review the wind speeds in KS 0226:1977. KMD had been collecting data on wind speed from 1977 to 2021; it was vital that this collected wind data be incorporated to the development of Kenya's wind map.

\subsection{Gust Duration Conversion}

Based on statistics, the shorter the wind gust period, the higher the velocity. This fact did not imply less safety since a collapse due to wind would most likely occur because of a sustained wind speed of over 10 minutes and not a wind gust of three seconds. The wind gust duration was the main difference between CP3-Chapter V-2:1972 and KS EN 1991-1-4:2005. A Durst curve, shown in Figure 2, was employed to convert the threesecond gust to the 10-minute wind speed. A Durst curve is a statistical correlation between wind speeds over different wind speed durations [23].

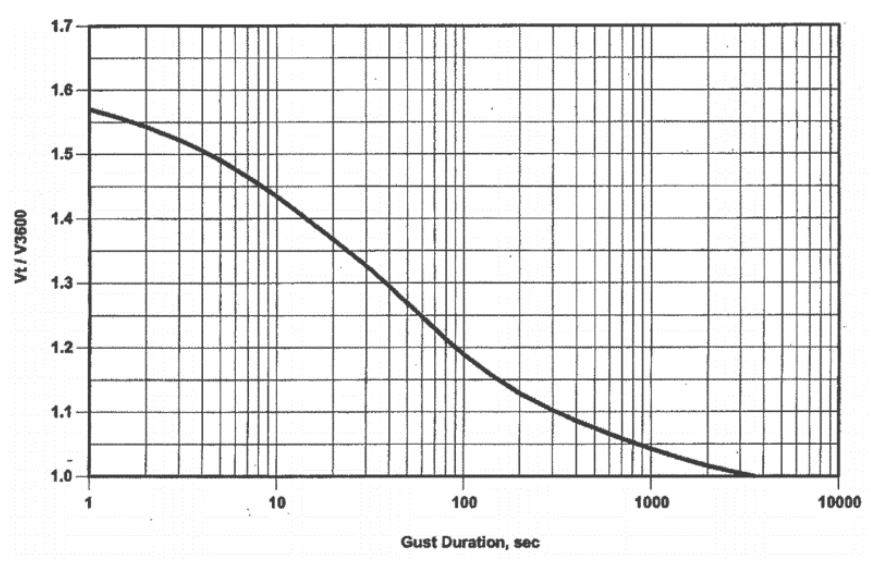

Figure 2: A Durst Curve.

\section{Discussion}

\subsection{Interpretation}

Kenya's method of determination of wind loads on structures deviated from the method presented in the UK NA. The wind duration in Kenya should be converted from $V_{3}$ to $V_{600}$. The peak velocity pressure should be calculated using Expression (4), Eqn (4.8) of KS EN 1991-1-4:2005 [4]. The exposure factor $c_{\mathrm{e}}(z)$ of Eqn (NA.3a) as proposed in the UK NA cannot apply in Kenya as argued previously in this paper.

\subsection{Integration}

\section{Conversion Procedure}

The Durst curve was used to convert the wind speeds given in KS 02-26:1977 Table 1 to either mean-hourly speeds or 10-minute wind speeds as shown [23]:

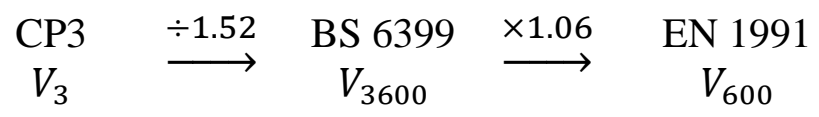

The values 1.52 and 1.06 are read off from the Durst Curve in Figure 2. This conversion was replicated in experimental studies; for example, when the UK updated their wind map from BS6399-2:1997 $\left(V_{3600}\right)$ to the Eurocode BS EN 1991-1-4:2005 $\left(V_{600}\right)$ it was found that the 10-minute wind speeds were $6 \%$ higher than mean hourly speeds [9]. That finding reinforced the accuracy and reliability of using the Durst Curve. Therefore, to convert the values of the wind speed from Table 1 to the Eurocode requirements, Expression (3) below could be used.

$$
V_{600}=\frac{V_{3}}{1.52} \times 1.06
$$

However, because of the three errors in Table 1 highlighted previously, the values in Table 2 are preferred in the determination of wind loads on structures. The wind speeds from Table 2 were converted from three-second gusts to 10-minute wind speeds using Expression (3), and the results were presented in Table 5. 


\begin{tabular}{|l|c|}
\hline Region & $\begin{array}{c}\text { Basic Wind Speed } \\
{\left[V_{600}\right](\mathbf{m} / \mathbf{s})}\end{array}$ \\
\hline $\begin{array}{l}\text { Nairobi, Central and Southern } \\
\text { Half of Eastern Province }\end{array}$ & 19.5 \\
\hline $\begin{array}{l}\text { Northern Half of Eastern and } \\
\text { North Eastern Province }\end{array}$ & 27.9 \\
\hline Coast Province & 21.6 \\
\hline Southern Part of Rift Valley & 25.1 \\
\hline Nyanza and Western Province & 32.1 \\
\hline \multicolumn{2}{|l|}{ Table 5: Proposed wind speeds when using the Eurocode. } \\
\hline
\end{tabular}

Table 5 showed five geographical regions in Kenya and their corresponding 10-minute wind speeds. It was difficult to generate isotachs with the data from Table 5 because it specified wind speed for large geographical areas and not single point locations like towns, as had been specified in Table 1. The lack of data at specific points made the generation of isotachs difficult. A wind map was therefore not developed. The data in Table 5 could suffice for the design of buildings in Kenya.

Once the wind speed was determined from Table 5, the engineer could then use the procedure outlined in KS EN 1991-1-4:2005. The peak velocity pressure was calculated using Eqn (4.8) of KS EN 1991-1-4:2005 reproduced as Expression (4). Eqn (4.8) was used and not Eqn (NA.3a).

$$
q_{\mathrm{p}}(z)=\left[1+7 I_{\mathrm{v}}(z)\right] \times \frac{1}{2} \rho v_{\mathrm{m}}^{2}(z)
$$

where:

$q_{\mathrm{p}}(z)$ - Peak velocity pressure at height $z$.

$I_{\mathrm{v}}(z) \quad$ - The turbulence intensity at height $z$.

$\rho$ - The density of air.

$v_{\mathrm{m}}(z)$ - Mean wind velocity at height $z$.

Expression (4) should be used with the recommended value of air density $\rho=1.25 \mathrm{~kg} / \mathrm{m}^{3}$. The procedure for getting the turbulence intensity $I_{\mathrm{v}}(z)$ and mean wind velocity $v_{\mathrm{m}}(z)$ was outlined in KS EN 1991-1-4:2005. After the calculation in Expression (4), the procedure in the UK NA could then be followed to determine the wind loads on the structure or parts of the structure.

\subsection{Implication}

The use of Expression (4) required the determination of the mean wind velocity $v_{\mathrm{m}}(z)$ and turbulence intensity $I_{\mathrm{v}}(z)$. The mean wind velocity at a height $\mathrm{z} v_{\mathrm{m}}(z)$ depended on the terrain roughness and orography. Turbulence intensity $I_{\mathrm{V}}(z)$ depended on the height above the ground level and ground roughness of the terrain upwind of the structure in the wind direction considered. The values of $v_{\mathrm{m}}(z)$ and $I_{\mathrm{v}}(z)$ are calculated from values read off from Table 4.1 of KS EN 1991-1-4:2005. Table 4.1 of KS EN 1991-1-4:2005 recommended the use of five terrain categories $(0$, I, II, III and IV) while the UK NA recommended three terrain categories (Sea, Country and Town). The UK NA lacked an equivalent to Table 4.1 and was therefore insufficient in the determination of the mean wind velocity $v_{\mathrm{m}}(z)$ and turbulence intensity $I_{\mathrm{v}}(z)$. Engineers in Kenya could therefore ignore the UK NA in the determination of the peak velocity pressure and adopt the recommendations of KS EN 1991-1-4:2005.

The value for Nairobi City's wind speed of $19.5 \mathrm{~m} / \mathrm{s}$ in Table 5 was similar to the value found in a separate study where wind data from eight weather stations around Nairobi City County in Kenya, was collected and analysed [7]. That study found that the wind speed $V_{600}$, in Nairobi City County varied from $18 \mathrm{~m} / \mathrm{s}$ to $22 \mathrm{~m} / \mathrm{s}$. That finding verified the conversion procedure of Expression (3) proposed in this paper. Since most structural engineers in Nairobi used a wind speed of $28 \mathrm{~m} / \mathrm{s}$ when determining wind loads on structures [24], adopting a wind speed of $19.5 \mathrm{~m} / \mathrm{s}$ instead of $28 \mathrm{~m} / \mathrm{s}$ resulted in a reduction of the magnitude of wind loads. This reduction may result in cost savings for building projects.

In summary, even though the UK NA could override KS EN 1991-1-4:2005, this study recommended that:

1. The UK wind map was be ignored in Kenya.

2. The altitude correction factor $c_{\text {alt }}$ in the UK NA was not to be used.

3. Eqn (NA.3a) should be ignored and Eqn (4.8) of KS EN 1991-1-4:2005 used.

4. The UK NA terrain classification (Sea, Country and Terrain) be ignored and instead the KS EN 1991-14:2005 terrain classification ( 0, I, II, III and IV) be used; and

5. The UK NA value of air density $\rho=1.226 \mathrm{~kg} / \mathrm{m}^{3}$ should be ignored and the recommended value $\rho=1.25 \mathrm{~kg} / \mathrm{m}^{3}$ of KS EN 1991-1-4:2005 be used.

Except for these five issues, the UK NA could be used in Kenya effectively for the determination of wind loads in the structural design of buildings. Others features that affect wind loading stated in the UK NA such as building shape, roof pitch, terrain shielding and building dimensions are appropriate for use in Kenya.

\section{Conclusion}

It was possible to use the Eurocodes for the structural design of buildings in Kenya before KEBS finalised on the development of the Kenya National Annexes. A combination of the local table values from Table 1 of KS 02-26:1977, the conversion procedure shown in this paper, and the UK NA could be used effectively to determine the wind loads on structures when designing to the Eurocodes in Kenya. 


\section{Recommendations}

1. Further research incorporating the latest data from KMD and other weather \& climate monitoring organisations should be conducted.

2. A design guide for the determination of wind actions on structures in Kenya according to KS EN 1991-1-4:2005 should be published and distributed to Kenya's engineers. The use of CP3-Chapter V2:1972 and BS 6399-2:1997 should be done away with.

3. A study to find out the density of air in Kenya should be conducted.

\section{References}

[1] American Meteorological Society, 'Glossary of Meteorology', Gust, Oct. 06, 2019. http://glossary.ametsoc.org/wiki/Gust.

[2] eMeteorology, Wind Gust and Sustained Wind What's the Difference? 2018.

[3] Republic of Kenya, 'Gazette Notice No. 13048', The Kenya Gazette, Nairobi, pp. 3417-3418, Sep. 14, 2014.

[4] CEN, 'EN 1991-1-4:2005+A1:2010 Eurocode 1: Actions on structures - Part 1-4: General actions Wind actions', European Committee for Standardization, 2010.

[5] KEBS, 'KS 02-26-1977', Kenya Bureau of Standards, 1977.

[6] National Planning and Building Authority, Kenya, 'KS Code: 2009 - Building Code of the Republic of Kenya - Planning and Building Regulations', 2009.

[7] E. 0. Onkendu, 'Preparation of Nairobi County Wind Map as Part of the Kenya National Annex to EN 1991-1-4', Master's Thesis, Pan African University Institute for Basic Sciences, Technology and Innovation, Juja, Kenya, 2014.

[8] KMD, 'Kenya Wind Speeds'. Kenya Meteorological Department, 1977.

[9] A. F. Hughes, P394 - Wind Actions to BS EN 1991 1-4. Steel Construction Institute (SCI), 2014.

[10]BSI, 'CP3 Chapter V-2:1972 - Basic Data for the design of buildings - Chapter V: Loading - Part 2: Wind Loads', British Standards Institute, 1972.

[11]BSI, 'BS 6399-2:1997 - Loading for Buildings Part 2: Code of practice for wind loads.', British Standards Institute, 1997.
[12]B. A. Harper, J. D. Kepert, and J. D. Ginger, 'Guidelines for converting between various wind averaging periods in tropical cyclone conditions.' World Meteorological Organization, Oct. 2008, Accessed: Oct. 06, 2019. [Online]. Available: https://www.wmo.int/pages/prog/www/tcp/Meetin gs/HC31/documents/Doc.3.part2.pdf.

[13]H. Gulvanessian, 'Eurocode: Basis of structural design', in The essential guide to Eurocodes transition, London, UK: British Standards Institute, 2010.

[14] The Kenya Engineer, 'Eurocodes to Impact Engineering practice in Kenya', Aug. 09, 2016.

[15]S. M. Shitote and J. Maina, 'Adoption and Use of the Eurocodes in Kenya', presented at the KEBS Training of Trainers, Machakos, Kenya, Sep. 2019.

[16]BSI, 'NA to BS EN 1991-1-4:2005+A1:2010: UK National Annex to Eurocode 1 - Actions on structures - Part 1-4: General actions - Wind actions', British Standards Institute, 2011.

[17]Atlas Big, 'Average Elevation of Countries Interactive Map', https://www.atlasbig.com/en-us, Oct. 06, 2019.

[18]CEN, 'EN 1991-1-3: Eurocode 1: Actions on structures - Part 1-3: General actions - Snow', European Committee for Standardization, 2010.

[19] AfricaNews, 'Kenya enjoys rare snowy feel, but meteo agency says it was hail storm', Jul. 15, 2017. https://www.africanews.com/2017/07/05/kenyaenjoys-rare-snowy-feel-but-meteo-agency-says-itwas-hail-storm/ (accessed Oct. 07, 2019).

[20]CEN, 'EN 1991-1-5: Eurocode 1: Actions on structures - Part 1-5: General actions - Thermal Actions', European Committee for Standardization, 2010.

[21] 'Definition of ISOTACH'. https://www.merriamwebster.com/dictionary/isotach (accessed Jun. 21, 2020)

[22] 'The Constitution of the Republic of Kenya'. Government Printer, Aug. 2010.

[23]P. Dregger, 'The Wind Investigator: How to Approximate Wind Velocities at Roof Level', IIBEC Interface, pp. 41-43, Oct. 2005.

[24]E. 0. Ong'ayo, S. K. Mwea, and S. O. Abuodha, 'Determination of Basic Mean Hourly Wind Speeds for Structural Design in Nairobi County', Int. J. Eng. Sci. Emerg. Technol., vol. 7, no. 2, pp. 631-640, Oct. 2014.

\section{Abbreviations}

$\begin{array}{ll}\text { Acronym } & \text { Meaning } \\ \text { BS } & \text { British Standard } \\ \text { BSI } & \text { British Standards Institute } \\ \text { CEN } & \text { European Committee for Standardization } \\ \text { EN } & \text { European Norm/ European Standard } \\ \text { IEK } & \text { The Institution of Engineers of Kenya } \\ \text { KEBS } & \text { Kenya Bureau of Standards } \\ \text { KMD } & \text { Kenya Meteorological Department } \\ \text { KS } & \text { Kenya Standard }\end{array}$

$\begin{array}{ll}\text { Acronym } & \text { Meaning } \\ \text { NA } & \text { National Annex } \\ \text { NDP } & \text { Nationally Determined Parameter } \\ \text { NICE } & \text { National Implementation Committee on the } \\ & \text { Eurocodes } \\ \text { UK } & \text { United Kingdom of Great Britain and } \\ & \text { Northern Ireland } \\ \text { USA } & \text { United States of America } \\ \text { WMO } & \text { World Meteorological Organization }\end{array}$

